\title{
O processo de morrer e a bioética na imprensa: uma análise psicossocial
}

\section{The process of the dying and bioethics in the press: a psychosocial analysis}

\section{El proceso de la muerte y la bioética en la prensa: un análisis psicosocial}

\author{
Edclécia Reino Carneiro de Morais* \\ Universidade Federal de Pernambuco - UFPE, Recife, Pernambuco, Brasil
}

\author{
Renata Lira dos Santos Aléssio** \\ Universidade Federal de Pernambuco - UFPE, Recife, Pernambuco, Brasil
}

Joanna Luiza da Cunha Pontes***

Universidade Federal de Pernambuco - UFPE, Recife, Pernambuco, Brasil

\section{Larissa de Siqueira Coelho****}

Universidade Federal de Pernambuco - UFPE, Recife, Pernambuco, Brasil

\begin{abstract}
RESUMO
Este artigo objetivou analisar o processo de morrer como notícia atrelada ao debate da bioética na impressa brasileira com base na Teoria das Representações Sociais. Foram selecionadas 45 matérias jornalísticas, publicadas entre o período de 2000 até 2013, as quais focalizavam o processo de morrer, a partir de um banco de dados composto por 531 matérias sobre bioética retiradas do acervo do jornal Folha de São Paulo. Os dados foram analisados com auxílio do programa Alceste. A cobertura analisada apresentou três eixos temáticos de produção de sentidos: questões sobre criogenia, prolongamento da vida na terminalidade e contornos práticos e axiológicos da autonomia do indivíduo. Destacamos que os tipos de circulação da questão do morrer aparecem atreladas às formas de se pensar a relação com o tempo. Nesse sentido, os conteúdos enfatizam dinâmicas de preservação e mudanças sociais.
\end{abstract}

Palavras-chave: Bioética, Morte, Representações Sociais, Imprensa.

\section{ABSTRACT}

This article was intended analyze the process of the dying as news linked bioethical debates in Brazilian press based on the Theory of Social Representations. Fourth five news was selected, published between the periods 2000 to 2003, which had focused on the process of dying from a database consisting of 531 articles on bioethics taken from the newspaper Folha de São Paulo. The data was analyzed using the Alcest program. The analyzed coverage presented three thematic areas of production of 
meaning: Questions about cryogenics, Prolongation on life in terminally and Practical and axiological contours of individual autonomy. We emphasize that the ways to die than issue of circulation appear linked to the ways of thinking about the relationship with the time. In this sense, the contents emphasize dynamic preservation and social changes.

Keywords: Bioethics, Death, Social Representations, Press.

\begin{abstract}
RESUMEN
Este artículo tuvo como objetivo analizar el proceso de morir como noticia relacionado a los debates bioéticos en la prensa brasileña, a luz de la teoría de las representaciones sociales. Fueron seleccionadas 45 noticias, publicadas entre los años 2000 y 2013 que se centró en el proceso de morir. Tales materias pertenecen a una base de datos que consta de 531 artículos sobre bioética tomadas del acervo del periódico Folha de São Paulo. Los datos fueron analizados utilizando el programa Alceste. La cobertura analizada presentó tres temas de la producción de significado: Preguntas sobre la criogenia, la prolongación de la vida en la terminal y contornos prácticos y axiológico de la autonomía individual. Señalamos que los tipos de circulación del proceso de morir aparecen vinculados a las formas de pensar la relación con el tiempo. En este sentido, los contenidos enfatizan la dinámica de preservación y cambios sociales.
\end{abstract}

Palabras clave: Bioética, Muerte, Representaciones Sociales, Prensa.

\title{
I ntrodução
}

Este artigo é produto de uma investigação exploratória sobre conteúdos veiculados por uma mídia impressa de ampla circulação nacional sobre o morrer dentro dos debates da bioética. Nesse sentido, teve-se o interesse de analisar os conteúdos que circularam em notícias jornalísticas sobre o processo de morrer no campo da bioética, investigando lógicas psicossociais que participam da construção de discursos acerca destes objetos.

A compreensão da morte sob o ponto de vista da circulação da bioética no espaço público exige o estudo das situações que aparecem como condições de emergência do debate (nascimento de controvérsias). São essas condições que levam os interlocutores a falar ou a omitir do debate público suas interrogações éticas sobre uma determinada prática (Bateman-Novaes, 1998).

Ao analisar os conteúdos veiculados em um jornal sobre o morrer no campo da bioética, torna-se fundamental considerar este meio como parte integrante na construção social da realidade. Não só numa perspectiva de transmissão de tal realidade, mas a partir de um olhar a longo prazo, por meio da participação destes meios nos processos de socialização, agendamento e enquadre (Mesquita, 2004). Parte-se do pressuposto de que os meios de comunicação destacam-se como "lugares de referência" (Correia \& Vizeu, 2008) para a população na busca por informações e, ao mesmo tempo, que os produtores da notícia são também sujeitos sociais. Desse modo, os critérios de 
noticiabilidade (que empregam valor à notícia) sofrem intervenção do momento histórico e do contexto social (Mattos \& Siqueira, 2005).

É preciso ressaltar que segundo Mesquita (2004) o discurso midiático ocupa um lugar de relevância na construção da realidade social, contribuindo para a formação de consensos sociais através da associação com um "poder ideológico". É através do recorte, da seleção, organização e sistematização da realidade que uma notícia é produzida. Dessa forma, os conteúdos veiculados pela mídia constituem-se enquanto um produto trabalhado, construído socialmente (Correia \& Vizeu, 2008).

O processo de produção de notícias pode assim estar atrelado a focalizações (Moscovici, 1976). De acordo com o autor, a focalização é um dos elementos que está na base das condições de emergência de representações sociais. Focalizar significa ressaltar alguns aspectos do fenômeno social, ocultando ou omitindo outros. Salientamos que a teoria das representações sociais se desenvolveu no esteio dos estudos sobre a imprensa, sobre a constituição e circulação de saberes acerca de objetos sociais controvertidos ou novos que irrompem no espaço público, como foi o caso da AIDS e da psicanálise (Herzlich \& Pierret, 2005; Moscovici, 1976).

Para Jovchelovitch (2001), elementos tradicionais e elementos de mudança são constantemente negociados na esfera pública. Tal esfera se caracteriza, segundo a autora, como um espaço de diálogo, que faz circular e produz representações sociais. Segundo Marková (2006), o estudo das representações sociais visa entre outros, a descobrir as formas pelas quais as circunstâncias de uma época contribuem para estabilidade e para a dinâmica de um dado fenômeno social. É por este motivo, que apresentamos brevemente alguns elementos históricos como forma de contextualizar o problema do morrer no campo da bioética.

A bioética configura-se como uma área emergente que faz convergir diversos saberes para "um campo aplicado aos conflitos morais em saúde" (Diniz, 2009, p. 207). De acordo com Bateman-Novaes (1998) a bioética é um objeto multidimensional cuja unidade pode ser estabelecida através do estudo dos conflitos que opõem diferentes visões de mundo organizadas em sistemas de ações em torno de questões normativas.

As decisões sobre o processo da "boa morte", sobre como, onde e de que modo se pode morrer, assim como quem é investido de poder decisório sobre tal processo, constituem um exemplo deste campo caracterizado por tomadas de posições conflituosas. Diferentes grupos sociais aparecem implicados na defesa de valores e crenças, uma vez que envolvem dimensões culturais, religiosas, políticas ligadas à autonomia e "referentes à gestão da pessoa" (Gomes \& Menezes, 2008). Nesse sentido, acentuam-se os dilemas bioéticos acerca da determinação dos limites da vida. 
Fronteiras entre a vida e a morte - controvérsias e conflitos bioéticos

A partir do séc. XVIII o saber médico, fundado na ciência, assume o status de verdade sobre os conhecimentos dos limites da vida e da morte no ocidente (Gomes \& Menezes, 2008). É nesse contexto, de ascensão da ciência, que o saber médico passa a ser reconhecido como importante interlocutor para a definição das fronteiras entre a vida e a morte.

Segundo Kovács (2003), com o atual excesso de práticas e intervenções no campo das ciências médicas, a partir da intenção de buscar cura e salvar vidas, surge um impasse que suscita polêmicas e controvérsias na cena pública. A sociedade contemporânea passa a se questionar sobre os limites dessas intervenções em situações de "missão impossível", como denomina a autora. Ou seja, quando a manutenção da vida se destina a práticas de sofrimento excessivo com a única função de retardar o processo do morrer.

Nesse contexto, uma das formas de problematizar esses limites diz respeito à nomeação das diferentes práticas que se fazem presentes em tais situações. São elas: a distanásia, a eutanásia e a ortotanásia. Segundo Gomes e Menezes (2008), a distanásia ou obstinação terapêutica se caracteriza pela realização de excessivas intervenções médicas com o objetivo de prolongar a hora da morte, com sofrimento ou "encarniçamento terapêutico". A distanásia é uma prática muito combatida por profissionais do movimento de cuidados paliativos, que defendem a qualidade de vida e o resgate da dignidade no processo do morrer (Kovács, 2003).

A eutanásia define um conjunto de práticas de interrupção da vida de pessoas com doença terminal ou incurável. O uso desse termo é plural e pode variar em função do seu status legal em cada contexto social, ou do posicionamento do autor que a define. De modo geral, alguns autores buscam acentuar a distinção entre eutanásia e ortotanásia, destacando o processo (ativo) de apressar a morte como característica essencial da primeira. Enquanto que a ortotanásia se caracterizaria apenas em situações cujo processo ocorre de forma "natural", direcionadas ao não adiamento da morte (Gomes \& Menezes, 2008; Kovács, 2003).

No conjunto de práticas relacionadas à ortotanásia está a suspensão do esforço terapêutico, que se trata da interrupção de tratamentos que se destinem apenas ao adiamento da morte, como nutrição, hidratação e respiração artificial. Esse procedimento possui como finalidade o afastamento da obstinação terapêutica (distanásia), ou dos obstáculos para a morte natural (Ribeiro, 2006).

As práticas de suspensão da obstinação terapêutica ou de antecipação da morte causam constantes polêmicas na arena pública do país. Segundo Gomes e Menezes (2008), esses debates são travados no mundo ocidental, principalmente entre grupos religiosos 
(fundados na tradição judaico-cristã) e movimentos sociais com finalidade em influenciar reformas na legislação vigente. Por um lado, grupos se posicionam defensores da autonomia individual e dos direitos sobre a vida, apoiando a regulamentação da eutanásia. Por outro lado, encontram-se também movimentos contrários, baseados em crenças religiosas que se apoiam na santidade da vida como condição de impedimento para estas práticas (Felix et al., 2013; Gomes \& Menezes, 2008).

A bioética entra nos debates e posicionamentos da comunidade científica e da população em geral por mobilizar comunicações, crenças e atitudes referentes à autonomia e à heteronomia da vida humana. Vale ressaltar que esses posicionamentos muitas vezes se localizam entre os polos da autonomia - heteronomia, de modo que as escolhas tornam-se situadas nos contextos e especificidades de cada caso, muitas vezes mesclando princípios e crenças diversas (Diniz \& Almeida, 1998). Segundo Menezes e Ventura (2013, p. 224) "o direito à autonomia e a crença em um processo natural do morrer constituem peças-chave na construção argumentativa da classe médica".

No campo legislativo as variações contextuais e as controvérsias também são muito presentes, e muitas vezes refletem a arena de conflitos sociais dos embates bioéticos em torno de variadas concepções sobre a morte e sobre a assistência ao morrer. Por exemplo, países como Holanda e Bélgica possuem regulamentação sobre a eutanásia desde o início dos anos 2000, com leis que a permitem. No Brasil, a legislação assegura o direito à vida com autonomia, entretanto não há referências claras sobre o direito à morte. Nesse contexto, práticas como eutanásia são consideradas ilegais, e alguns órgãos de classe reivindicam a tipificação desta enquanto crime de homicídio (Menezes \& Ventura, 2013).

Já em relação à prática de "suspensão de esforço terapêutico", há várias referências favoráveis no sistema jurídico brasileiro, tanto a nível federal com a Constituição Federal (art. 1.o, III, e art. 5.0, III), o Código Civil (art. 15) e a Lei Orgânica da Saúde (Lei n. 8.080/90, art. 7. O, III), quanto em regimentos de classe, como no Código de Ética Médica - Resolução no 1.805/2006 - (Ribeiro, 2006). A aprovação da Resolução no $1.805 / 2006$ pelo Conselho Federal de Medicina (CFM) que classifica e normatiza a suspensão do esforço terapêutico, enquanto prática possível, embasada em uma assistência integral e voltada para o respeito da vontade do paciente no contexto hospitalar, provocou muitos embates entre órgãos de classe (CFM e Ordem dos Advogados do Brasil - OAB/SP) (Gomes \& Menezes, 2008). Observamos assim, que a questão da morte enquanto conflito moral no campo da saúde é investida por diferentes atores sociais (médicos, advogados, religiosos, pacientes), tornando-se um objeto de disputa. Ressaltamos ainda que 0 aperfeiçoamento de técnicas para 
manutenção da "vida artificial" reforça o clima de interrogações acerca dos limites éticos de tais práticas.

Segundo Moscovici e Doise (1992), existem três instâncias que estão na base das tomadas de decisão sobre assuntos polêmicos em uma sociedade: a tradição, a ciência e o consenso. Para os autores, este último, seria atualmente, a instância mais resistente, por possibilitar a exposição dos diferentes pontos de vista na intenção de congregálos e construir um entendimento comum a todos e legitimado socialmente. A eficácia do consenso estaria, assim, associada a uma postura democrática dos grupos que estão no debate, com fins de estabelecer normas e modelos de ação passíveis de adesão e implicação social. De acordo com Bateman (2004), a dimensão moralmente problemática de um objeto social pode ser estudada através do exame de seus aspectos públicos e institucionais. Dessa forma, a investigação da circulação de um objeto social na cena pública através de notícias jornalísticas possibilitará considerações sobre a espessura social deste objeto, como um termômetro social.

Bateman (2004) afirma que a questão do fim da vida foi objeto de longos debates nos EUA e na Inglaterra muito antes dos anos 60, entretanto, só foi se tornar um tema de atualidade na França no final do século XX. Aspectos que evidenciam as variações de relevância social que um objeto sofre em diferentes culturas e sociedade. Em relação ao Brasil, podemos afirmar que há uma escassez de pesquisas sobre a transformação do processo de morrer em tema de debate na imprensa (o processo de morrer como notícia) do ponto de vista da bioética.

Por outro lado, alguns estudos sobre o aborto como notícia no Brasil demonstram que entre os temas paradigmáticos da bioética, este se caracteriza como bastante presente na agenda de debates da mídia impressa brasileira (Fontes, 2012; Melo, 2001; Pazello \& Corrêa, 2002). Entretanto, Melo (2001) chama atenção para o modo descontínuo no qual esses debates se apresentam. De modo que, as publicações oscilam entre fases de fervorosos debates e fases de menor incidência, assim como a ênfase em determinados posicionamentos ou cobertura das tensões legislativas sobre a prática que aparecem e desaparecem da cena pública.

Neste contexto em movimento, conhecer as formas pelas quais a imprensa brasileira tem tratado a questão do processo de morrer no campo da bioética, à luz da teoria das representações sociais, pode nos informar sobre das lógicas psicossociais que participam da construção de discursos acerca destes objetos. Como afirmam Dany et al (2009), além de descrever o que se fala sobre os objetos, este tipo de análise permite estudar o que é colocado em jogo (questões políticas, societais, ideológicas) na articulação entre o que é ou não é dito. 


\section{Método}

\section{Procedimentos de coleta}

O levantamento dos dados foi realizado a partir do acervo do Jornal Folha de São Paulo. Esta mídia é uma fonte amplamente utilizada em pesquisas no âmbito da teoria das representações sociais, em virtude de sua ampla circulação a nível nacional e consequentemente sua forte penetração (Simoneau \& Oliveira, 2015).

Em um primeiro momento, foi utilizado como descritor o termo: bioética. As matérias foram selecionadas desde 1983, data em que observamos a primeira menção ao termo no jornal, até julho de 2013. Através da primeira etapa da coleta, foram encontradas 531 matérias jornalísticas que contêm a palavra bioética em seu conteúdo. O jornal em questão pode publicar conteúdos ligados ao campo da bioética sem utilizar o termo. Entretanto, compreendemos que a utilização da palavra bioética circunscreve os conteúdos em um campo delimitado pelo próprio veículo, havendo assim uma intenção explícita de enunciação. Portanto a primeira seleção de matérias para esta pesquisa se deu a partir exclusivamente do termo Bioética.

Após uma análise temática do corpus principal foram identificadas 45 matérias que têm como foco de debate o morrer em situações de conflitos éticos (eutanásia, ortotanásia e distanásia), sendo a primeira publicação no ano 2000. A análise do presente artigo está centrada no conteúdo dessas 45 matérias.

\section{Procedimentos de análise}

Os dados foram analisados com auxílio do software ALCESTE que extrai, a partir da co-ocorrência e frequência (teste de khi2) de palavras, as informações mais importantes de um texto, distribuindoas hierarquicamente em classes de palavras. O software classifica 0 texto em conjuntos de unidades textuais compostas pelas palavras mais características de cada classe, chamadas unidades de contexto elementar (UCEs) e ainda aponta as palavras que se caracterizam ausências significativas para cada classe.

Cada matéria foi inserida, no arquivo de dados do software, precedida da seguinte linha estrelada: **** * ${ }^{*}{ }_{u j} X X{ }^{*} E s p_{-} X X$ *Ano_XX. A variável *Suj_diz respeito a numeração atribuída a cada matéria; A variável ${ }^{*} \mathrm{Esp}_{\text {_ }}$ diz respeito ao produtor do discurso veiculado. Havia a opção: *Esp_1 - para especialistas da área (médicos, advogados, pesquisadores); *Esp_2 - para não especialistas (jornalistas e opinião pública); e *Esp_3 - para matérias escritas representantes religiosos. Do total de matérias analisadas, trinta e duas foram escritas por jornalistas e opinião pública, doze por especialistas (pesquisadores de bioética, médicos, juristas e 
sociólogos) e uma por padres. A última variável, *Ano_, se refere ao ano de publicação das matérias.

Segundo Nascimento e Menandro (2006) o software ALCESTE está embasado em um pressuposto segundo o qual a especificidade de um vocabulário irá informar sobre diferentes formas de pensar, e nesse sentido, os diferentes pontos de referência do produtor do discurso ou inserções sociais dos sujeitos, também poderão produzir diferentes mundos lexicais. Nesse sentido, a interpretação dos dados foi realizada a partir da reconstituição do sentido das classes, buscando-se identificar campos léxicos de distribuição dos debates sobre o processo de morrer em meio a conflitos bioéticos.

\section{Resultados e Discussão}

A figura 1 ilustra o dendrograma oriundo da classificação hierárquica descendente das palavras que compõem os discursos jornalísticos sobre o processo de morrer e os limites da vida no campo da bioética. Observa-se que $80 \%$ do corpus original foram classificados através da classificação automática do software ALCESTE.

Três eixos norteadores organizam os conteúdos veiculados pelo jornal investigado. O primeiro que nomeamos: Questões sobre criogenia envolve o questionamento acerca das técnicas de criogenia e congelamento de pessoas. O segundo nomeado: Prolongamento da vida na terminalidade - trata da distanásia e da ortotanásia. O terceiro eixo: Contornos práticos e axiológicos da autonomia do indivíduo - concentra os tensionamentos práticos, normativos e de valor que circunscrevem a noção de autonomia do indivíduo. A seguir apresentamos cada uma das classes que compõem os três eixos identificados, de forma a explicitar seus respectivos conteúdos e a construção de sentidos que justifica suas nomeações. 


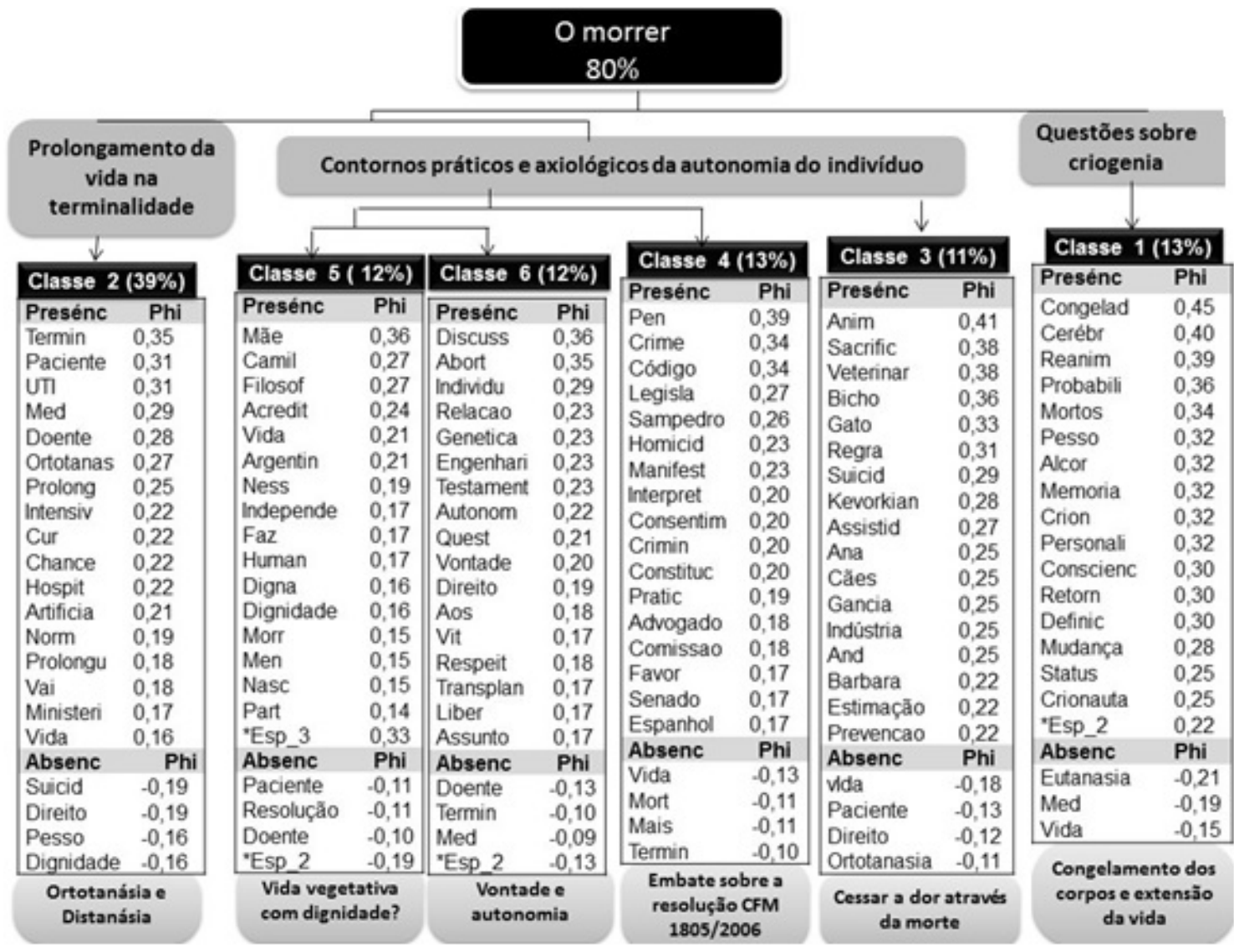

FIGURA 01 - Dendrograma da Classificação Hierárquica Descendente sobre o morrer.

O eixo 1 - Questões sobre criogenia - é composto por uma matéria jornalística representativa da classe 1 que contém $13 \%$ das unidades textuais classificadas. São palavras significativas da classe: congelado, cérebro, reanimação, probabilidade e mortos. A primeira classe - congelamento dos corpos e extensão da vida - discute a extensão da vida a partir da criogenia humana, um método que submete os corpos a um processo de congelamento, e a possibilidade destes serem reanimados com sucesso. Em primeira instância leva-se em consideração o status dos congelados: seriam eles considerados mortos ou vivos? Embora haja uma classificação de morte para estes corpos, a possibilidade de reanimação e reinserção abre margem para que sejam reconhecidos como pacientes ao invés de cadáveres:

O principal motivo para os crionistas se preocuparem com a definição de seu status é que muitos gostariam de ser congelados antes de legalmente mortos, de ser tratados como pacientes em unidades de emergência em vez de cadáveres.(*Suj_07 *Esp_2 *Ano_2001)

Observa-se ainda uma analogia entre indivíduos congelados e indivíduos em estado de coma, problematizando questões da ordem 
da consciência como um marcador fundamental da vida numa lógica cerebral, que constitui principalmente o armazenamento de informações. Embora a tecnologia venha a convencer que os "suspensos" poderão ser reanimados com sucesso, a espera pelos resultados satisfatórios poderia produzir danos graves e/ou até mesmo irreversíveis:

Claramente os congelados não preenchem uma definição baseada na consciência da vida como percepção contínua em vigília, muito menos personalidade autoconsciente [...] pessoas dormindo ou em coma temporário tem probabilidade suficiente de retornar a personalidade consciente para continuar possuindo direitos de pessoas vivas (*suj_07 *Esp_2 *Ano_2001).

Podemos identificar neste discurso, uma tentativa de apreensão de uma realidade estranha e não-familiar (Bauer, 2011). Tal forma de apreensão se manifesta através de analogias, que segundo Moscovici (1976) ajudam a fundar as características do objeto (a criogenia) através da generalização de um conceito antigo (o coma).

A criogenia aparece ainda como uma "tecnologia da esperança", ou seja, uma "ferramenta médica dotada de uma capacidade potencial de preservar ou de prolongar a vida" (Leibing \& Tournay, 2010, p. 03). Trata-se de um tipo de biotecnologia cuja realização resta constitutivamente incerta. Segundo as autoras, são "tecnologias que despertam alto grau de esperança cujas práticas concretas são engendradas concomitantemente à criação de cenários sobre 0 futuro" (2010, p. 04). De forma que, as tecnologias da esperança não precisam de provas científicas para gerar credibilidade, ao contrário, elas são uma aposta coletiva de que vale a pena "esperar".

Nesse contexto, a criação de um "soi-technologique" aparece além do concebível e do improvável (Leibing \& Tournay, 2010). No exemplo da classe é possível identificar esta criação através dos questionamentos sobre a possibilidade da manutenção da personalidade do "crionauta". Em outras palavras, uma problematização sobre as possibilidades de construção de subjetividade pós-descongelamento. Este primeiro eixo aparece composto por apenas uma matéria possivelmente em virtude da temática destacada do congelamento dos corpos, que se diferencia dos outros dois eixos temáticos como apresentamos a seguir.

O segundo eixo - Prolongamento da vida na terminalidade - é representado pela classe $\mathbf{2}$ - Ortotanásia e distanásia. A classe 2 trata do prolongamento da vida em situação de terminalidade e possui $39 \%$ das unidades textuais classificadas. São palavras significativas desta classe: terminal, paciente, UTI, doente, ortotanásia. Entrevistas definem desde ortotanásia, como uma 
prática em que se removem as intervenções artificiais de prolongamento da vida, até métodos de excessivas intervenções para um prolongamento que caracteriza uma obstinação terapêutica, como a distanásia. Esta classe descreve ainda o caso do ex-governador de São Paulo, Mário Covas que sancionou e se beneficiou de uma lei que autoriza os pacientes terminais a escolher o local de sua morte (evitando prolongamentos que podem ser dolorosos).

O caso Covas foi emblemático tendo motivado discussões por uma resolução nacional do Conselho Federal de Medicina. Conforme apresentado anteriormente, em 2006 o CFM aprovou uma resolução (CFM-1805/2006) que foi contestada pelo Ministério Público Federal. Esta classe evidencia a ambivalência vivenciada pelos médicos, que tratam eutanásia como equivalente à ortotanásia:

Covas, que morreu há quatro anos em decorrência de um câncer na bexiga, beneficiou-se dessa lei. Nos conselhos regionais de medicina, a tendência é de aceitação da eutanásia, embora os médicos prefiram tratá-la como ortotanásia, que seria o ato de retirar equipamentos ou medicações que servem para prolongar a vida de um doente terminal (*Suj_012 ${ }^{*} E s p \_2$ *Ano_2005).

Segundo Marcos de Almeida, professor da UNIFESP, Universidade Federal de São Paulo, isso é feito de monte. Especialistas em bioética defendem a chamada ortotanásia (*Suj_022 *Esp_2*Ano_2005).

Segundo Menezes e Ventura (2013) esta ambivalência parece se revelar na ideia de que o médico pode ser representado como algoz (alguém que realiza um ato nefasto contra outra pessoa) ou como vítima (alguém refém de uma situação insolúvel). Neste contexto, falar de eutanásia se torna um "tabu". Assim, essa palavra é silenciada e em seu lugar, a ortotanásia assume uma legitimidade nos discursos.

A ênfase dada à ortotanásia é investida por conteúdos que parecem traduzir uma "cobertura simpática" (Rosemberg \& Andrade, 2012) à prática. Ressaltamos que neste eixo encontramos $39 \%$ das unidades textuais classificadas, elemento que pode corroborar nossa interpretação de que a questão da ortotanásia ocupa um lugar de destaque. A ideia subjacente é de que o tempo presente vivido deve ser o melhor possível para o paciente e que este deve ser ouvido e ter um papel ativo no processo decisório. Chama a atenção, entretanto, a quase ausente discussão acerca dos cuidados paliativos entre conteúdos que tratam de cuidados e tomadas de decisões no fim da vida, uma vez que, parecem resumidos à prática da ortotanásia. 
No terceiro eixo - Contornos práticos e axiológicos da autonomia do indivíduo - observamos uma maior heterogeneidade de sentidos e posicionamentos sobre a morte e o morrer. Ao observar o dendrograma é possível perceber que neste eixo aparecem informações e posicionamentos que debatem situações de antecipação da morte ou de interrupção da vida tanto no animal quanto no humano. É composto pelas seguintes classes: Classe 3 Cessar a dor através da morte; Classe 4 - Embates sobre a resolução do CFM 1805/2006; Classe 5 - Vida vegetativa com dignidade e classe 6 - Vontade e autonomia.

A Classe 3 - Cessar a dor através da morte - apresenta, na maioria das UCEs ( $11 \%$ das unidades textuais classificadas), discursos sobre a questão do alívio da dor e do sofrimento através da morte. São palavras significativas desta classe: animal, sacrifício, veterinário, bicho, gato, suicídio. A eutanásia recebe ênfase nesta classe, através das oposições entre animais não humanos e humanos. Duas questões são evidenciadas: a nova resolução do Conselho Federal de Medicina Veterinária (CFMV-1000/2012) que amplia a regulamentação da eutanásia em animais e posicionamentos sobre eutanásia e suicídio assistido em humanos.

De um lado, os discursos apresentam reações divergentes à modificação na resolução do CFMV (1000/2012), sobre eutanásia em animais que causam alto custo de tratamento somado à baixa expectativa de cura:

Ninguém está falando em matar animais/saudáveis, a regra vale apenas para os doentes que representam alto custo. Tratar uma vaca não é como cuidar de um gato dentro de casa diz, Fortes (*Suj_44*Esp_2 *Ano_2012).

Para a empresária e protetora de gatos: Eunice Lima, 42, a nova regra é desumana. O fazendeiro tem que colocar em sua planilha de custos que os bichos também adoecem e precisam de tratamento. Não existe isso de matar só porque é caro cuidar (*Suj_44*Esp_2 *Ano_2012).

Os discursos favoráveis a nova regra do CFMV (1000/2012) revelam uma diferenciação entre o tratamento oferecido a animais domésticos e não domésticos. Enquanto que os discursos contrários à nova resolução ressaltam a não diferenciação no que diz respeito ao cuidado.

De acordo com Doise (1990, p. 144), o pensamento social é marcado pela "onipresença de certas relações simbólicas: relações que opõem humanos e animais, indivíduos e grupos, homens e mulheres". Estas oposições são princípios organizadores que intervém em variadas representações sociais. Assistimos atualmente, a crescente 
preocupação com o bem-estar animal. A esta preocupação identificamos uma tendência a relativizar a distância entre "humanos" e "animais", o que pode indicar novas formas de pensar as relações simbólicas entre os dois.

De outro lado, referindo-se aos humanos, a classe revela uma posição favorável à eutanásia, ligada a descrição da morte de Oscar Wilde e posições contrárias à eutanásia e ao suicídio assistido manifestadas em defesa da prevenção ao suicídio:

Quando Oscar Wilde abandonou os tratamentos e encomendou a sua farra final, sabia que a farra seria final. Mas Wilde não foi caso único (*Suj_041*Esp_2*Ano_2011).

Isso pode provocar naquele que sente dor ou está muito doente uma pressão para escolher o suicídio assistido. Contudo, estudos mostram que, quando a prevenção adequada é oferecida, mesmo os mais doentes ou deficientes com propensão ao suicídio mudam frequentemente de ideia (*Suj_040*Esp_2*Ano_2010).

Quando o ato de decidir sobre a eutanásia está ligado ao animal, duas ênfases parecem opor os posicionamentos: uma realça a questão da afetividade vinculada à animais domésticos; e a outra destaca implicações econômicas de custo/benefício no cuidado de animais de grande porte. Tratando-se de humanos, é difícil identificar a base de sustentação dos posicionamentos sobre a eutanásia, de modo que os mesmos remetem a análises mais singulares ("cada caso é um caso").

A classe 4 - Embate sobre a resolução CFM 1805/2006- divide opiniões acerca da resolução do CFM 1805/2006 que autoriza os médicos a limitar ou suspender tratamentos a doentes em fase terminal. O CFM defende esse procedimento, justificando cessar um sofrimento irreversível aos pacientes. Enquanto a OAB/São Paulo contesta a prática tipificando-a como homicídio.

Pelo contrário, o cessar de um sofrimento irreversível acaba trazendo paz para todos, do ponto de vista legal, ainda estamos sob a égide de um código penal anacrônico, construído nos anos 40, quando mal havia sido descoberta a penicilina (*Suj 009 *Esp_1 *Ano_2003).

Resolução é um crime, diz promotor. Para o presidente da Comissão de Bioética e Biodireito da OAB/SP, Erickson Gavazza Marques, os médicos que seguirem a nova resolução do CFM poderão responder a processo criminal (*Suj_32 * Esp_2 * Ano_ 2006) 
Vale ressaltar que o jornal utiliza o termo eutanásia para nomear as intervenções previstas na resolução do CFM, em outras palavras a prática de suspensão de tratamento prevista no documento é veiculada como autorização para eutanásia. Entretanto, o documento esclarece que os procedimentos autorizados não se caracterizam como eutanásia.

A classe 5 - Vida vegetativa com dignidade? - é constituída por $12 \%$ das unidades textuais classificadas. O vocabulário desta classe apresenta palavras como mãe, Camila, filosofia, filósofos, vida, argentina, digna, dignidade, morrer. Parece tratar do tema do fim da vida a partir de uma atitude positiva em relação aos cuidados paliativos ou à ortotanásia nos casos de vida vegetativa:

O caso da menina argentina Camila de 3 anos que permaneceu em estado vegetativo desde o nascimento, mobilizando seus familiares em busca da suspensão do esforço terapêutico, se tornou um marco na discussão sobre a "boa morte". Este caso é focalizado na classe 5 como forma de ilustrar um posicionamento favorável ao "deixar morrer" em detrimento de manter a vida através de aparelhos:

Mãe de uma outra menina, de oito anos, e professora de um jardim de infância, Selva diz que não crê que Camila tenha morrido em vão. Creio que ela veio ao mundo para fazer aprovar essa lei. É preciso impedir que outros sofram tortura terapêutica. A aplicação da lei agora é discutida em outro caso que virou uma espécie de novela na Argentina (*Suj_45 *Esp_2 *Ano_2012).

A Argentina aprovou em 2012 uma lei que favorece cuidados paliativos e que autoriza o paciente (ou familiar) a decidir se mantém tratamento intensivo no fim da vida. A lei foi chamada de Lei da Morte Digna e acendeu o debate no contexto brasileiro. O discurso desta classe mostra o papel ativo que o paciente pode ter nas tomadas de decisão, quando narra os últimos dias do ex-governador do estado de São Paulo, Mário Covas:

Ao ser internado no INCOR, recusou-se a ir para a UTI perderia contato com mulher e filhos. Estou administrando minha ida, como disse a seu vice, Geraldo Alckmin (*Suj_08 *Esp_2 *Ano_2001).

Podemos observar que esta classe aparece investida pelo discurso de padres mais progressistas dentro da Igreja Católica, que discutem a qualidade de vida dos pacientes vegetativos e terminais:

Essa condição de existir não é uma patologia! Quando esquecemos isso, acabamos caindo na tecnolatria e na 
absolutização da vida biológica pura e simplesmente. Insensatamente, procuramos a cura da morte e não sabemos mais o que fazer com os pacientes fora de possibilidades terapêuticas (*Suj_10*Esp_3*Ano_2003).

De acordo com Gomes e Menezes (2008) a Conferência Nacional dos Bispos do Brasil (CNBB) não é contrária à ortotanásia. É importante ressaltar segundo Luna (2010) que a igreja católica tem produzido documentos contrários à eutanásia e à obstinação terapêutica e favoráveis à "morte natural". Nesses textos, a natureza representa a vontade divina e a "morte natural" significa cumprir os desígnios de Deus. Assim, os princípios da ortotanásia vão ao encontro do ideal da "morte natural" que é um dos pilares do magistério da igreja católica (Luna, 2010).

A classe 6 - Vontade e autonomia - possui $12 \%$ das unidades textuais classificadas. São palavras significativamente associadas a esta classe: discussão, aborto, indivíduo, relação, genética, engenharia, testamento, autonomia. Como exemplo dos conflitos e limites da efetivação da vontade e da autonomia do indivíduo, vários temas da bioética são ressaltados nessa classe. O tema do reconhecimento da autonomia do indivíduo aparece ligado às escolhas dos pacientes:

Como contribuições às soluções desejadas, estão as formas seguras de antecipação da vontade, como o testamento vital documento no qual a pessoa consigna suas vontades quanto aos cuidados médicos que pretende ou não receber (*Suj_13*Esp_2*Ano_2005).

Nestes casos, é preciso supor que os pacientes estejam em condições de avaliar e opinar em relação a procedimentos médicos futuros. Outro exemplo sobre o conflito no reconhecimento da autonomia do indivíduo, aparece na discussão sobre o aborto e a eutanásia, a partir de dois posicionamentos antagônicos que tratam desta relação. Um primeiro que separa as duas problemáticas:

A discussão deve se pautar sobre pessoas capazes de ponderar sobre sua própria existência, mas há uma tendência a se pensar sempre questões como as do aborto e da eutanásia como uma relação em que um é o assassino e o outro é a vítima indefesa (*Suj_24 *Esp_2 *Ano_2005)

E o segundo posicionamento que trata a questão do aborto como a morte de um indivíduo, tomando o feto como vítima: 
Mas como pós-graduado na área de ciências biológicas, tenho plena conviç̧ão de que o aborto envolve a morte de um ser humano. Isso é fato, e acho surpreendente que se desvie dessa verdade durante as discussões, falando-se de tudo, menos da vítima (*Suj_21*Esp_1*Ano_2005).

O trecho acima referenciado remete à ideia de "vítima" - termo usado no direito para reconhecer a pessoa. Destaca-se a partir do discurso de especialista, na matéria, uma concepção de pessoa como propriedade da natureza. Recorre-se, assim, ao argumento da ordem natural para justificar o fundamento biológico da pessoa que reside na imagem do embrião enquanto vida humana.

O debate sobre a autonomia do indivíduo parece atrelado à discussão sobre a noção de pessoa. O embrião aparece aqui precocemente representado como sujeito autônomo, um sujeito de direito, uma pessoa. Nos trechos selecionados, o caso do aborto encarna à polarização entre reconhecer ou não a autonomia do embrião outorgando-Ihe ou não, o estatuto de pessoa. De acordo com Gomes e Menezes (2008), a concepção de pessoa específica à Modernidade é fundada no individualismo. Segundo as autoras,

o aborto e a eutanásia cada vez mais se apresentam como questões centrais na contemporaneidade, por indicarem não apenas a delimitação das fronteiras entre vida e morte, mas por constituírem temas que revelam tensões quanto à noção de pessoa no Ocidente e seus direitos (Gomes \& Menezes, 2008, p. 81).

Por fim, subjacentes aos conteúdos veiculados pelo jornal, vimos emergir algumas antinomias que parecem organizar as tomadas de posição acerca das formas práticas do desenrolar da morte, tais como: vida artificial $\mathrm{x}$ vida natural; morte digna $\mathrm{x}$ morte indigna; moral $x$ imoral ou humano $x$ não-humano. De acordo com Marková (2006) estas antinomias podem se constituir em thêmata quando, no curso de eventos históricos e sociais, elas traduzem problemas, concentrando atenção e atuando como fontes de tensão e de conflito. Ao penetrar no discurso público, podem começar a gerar representações sociais. Para a autora, thêmata são questões sobre as quais os debates públicos se debruçam, algumas podendo aparecer de forma perpétua na arena pública (thêmata de base) em função de atualizações conjunturais, históricas, societais e culturais.

Identificamos a thêmata do reconhecimento social, descrita por Marková (2006), como sendo uma thêmata de base por aparecer enquanto essencial à vida em sociedade. De acordo com a autora, o reconhecimento social "é um esforço social básico - ou desejo direcionado aos outros humanos" (2006, p. 256). Esta thêmata 
traduz o desejo do indivíduo de ser tratado com dignidade pela sociedade ao mesmo tempo em que a sociedade exige um comportamento digno deste indivíduo. No conteúdo analisado, o reconhecimento social mostra o conflito que existe na demarcação da autonomia nos casos dos doentes terminais, notadamente nas tensões entre autonomia $\mathrm{x}$ dependência; dignidade $\mathrm{x}$ indignidade; moral x imoral.

\section{Considerações finais}

A cobertura analisada apresentou três eixos temáticos de produção de sentidos: a questão da criogenia, a questão da ortotanásia e a problematização da autonomia do indivíduo. Destacamos que as formas de circulação do processo de morrer, face a conflitos éticos, aparecem atreladas às formas de se pensar a relação com o tempo. A orientação para o tempo futuro (eixo 1) é assim focada no tocante à possibilidade de congelamento de corpos, suscitando interrogações acerca de manutenção/transformação da pessoa bem como de seu status enquanto "morta". Orientação para o tempo vivido (eixo 2) é focada na ideia de que o presente deve ser o melhor possível para o paciente, que tem o papel ativo no processo decisório em relação ao morrer.

No último eixo (eixo 3), observamos polarizações de opiniões e atitudes em torno da noção de autonomia e da pessoa: no caso da vida vegetativa, do desejo de finalizar a dor através da morte, da eutanásia de animais e da relação entre aborto e eutanásia. Podemos, entretanto, inferir que as polarizações apresentadas tendem a reforçar um clima ideológico favorável à construção e circulação de atitudes positivas à retórica da "boa morte".

De um lado, pela ênfase ao contexto internacional (Argentina, Holanda entre outros) que aparece como favorável à mudanças nas formas de acompanhamento do morrer. $E$ de outro, pela apresentação do protagonismo dos órgãos de classe no contexto nacional, tais como o Conselho Federal de Medicina (CFM), Conselho Federal de Medicina Veterinária (CFMV) ou ainda a Ordem dos Advogados do Brasil (OAB - seção nacional), apoiando reformas na atuação ou na legislação no sentido de garantir uma melhor assistência ao paciente em fase terminal. Destaca-se ainda, o papel desempenhado pela Conferência Nacional dos Bispos do Brasil (CNBB) e da Igreja Católica como interlocutores na construção de uma atitude favorável à ortotanásia e desfavorável à eutanásia.

Assim como no caso do aborto, conforme já afirmado, a discussão sobre a morte aparece atrelada aos debates legislativos e aos conflitos entre os órgãos de classe pela primazia dos argumentos e posições. Nesse sentido, os conteúdos veiculados pela mídia no 
contexto dos conflitos éticos tendem a enfatizar dinâmicas de preservação e mudança social.

Embora este artigo esteja limitado a apenas um veículo de imprensa, é preciso reconhecer que se trata de um dos jornais com maior circulação nacional. Observamos que a articulação entre o tema da morte e o campo da bioética no espaço público brasileiro é ainda recente, datando de menos de quinze anos para o veículo estudado. Acreditamos que estudos futuros são necessários para problematizar a nossa hipótese da atualização da thêmata do reconhecimento social, de forma a evidenciar dinâmicas de preservação e manutenção nas representações sociais da "boa" e da "má" morte. A dimensão moral deve ser aprofundada enquanto perspectiva social sobre objeto. As diferentes formas de nomear a morte no espaço público do debate bioético inscrevem o fenômeno em diferentes ordens normativas e axiológicas. É nesta pista que nossos próximos estudos pretendem seguir.

\section{Referências}

Bateman-Novaes, S. (1998). La bioéthique comme objet sociologique. Cahiers Internationaux de Sociologie - Nouvelle série - figures de la connaissance, (104), 5-32. Paris: Presses Universitaires de France. Recuperado de http://www.jstor.org/stable/40690765

Bateman, S. (2004). L'expérience morale comme objet sociologique. L'année Sociologique, 54(2), 389-412.

Bauer, M. (2011). A popularização da ciência como imunização cultural: a função de resistência das representações sociais. In P. Guareschi \& S. Jovchelovith (Orgs.), Textos em representações sociais $\left(12^{\mathrm{a}}\right.$ ed, p. 183-208). Petrópolis, RJ: Vozes.

Correia, J. C., \& Vizeu, A. (2008). A construção do real no telejornalismo: do lugar de segurança ao lugar de referência. In A. Vizeu (Org.), A Sociedade do Telejornalismo. (pp. 11-28). Petrópolis, RJ: Vozes.

Dany, L., Salas, S., \& Dudoit, E. (2009). Représentation sociales de l'euthanasie et des soins palliatifs dans la presse française. Médecine Palliative: Soins de Support-AccompagnementEthique, 0(0) 59-75. Galatasaray Üniversitesi İleti-ş-im Dergisi. Recuperado de http://dergipark.ulakbim.gov.tr/gsuilet/article/view/500007176 6

Diniz, D. (2009). Bioética e gênero. Revista Bioética, 16(2). Recuperado de 
http://revistabioetica.cfm.org.br/index.php/revista_bioetica/arti cle/viewArticle/68

Diniz, D., \& Almeida, M. de. (1998). Bioética e aborto. Iniciação à Bioética. Brasília: Conselho Federal de Medicina, 125-138.

Doise, W. (1990). Les représentations sociales. In R. Ghiglione, C. Bonnet, \& J.-F. Richard (Orgs.), Traité de psychologie cognitive 3 (pp. 111-174). Paris: Dunod.

Felix, Z. C., da Costa, S. F. G., de Melo Alves, A. M. P., de Andrade, C. G., Duarte, M. C. S., \& de Brito, F. M. (2013). Eutanásia, distanásia e ortotanásia: revisão integrativa da literatura. Ciência e Saúde Coletiva, 18(9), 2733-2746.

Fontes, M. L. A. (2012). O enquadramento do aborto na mídia impressa brasileira nas eleições 2010: a exclusão da saúde pública do debate. Ciência \& Saúde Coletiva, 17(7), 1805-1812.

Gomes, E. de C., \& Menezes, R. A. (2008). Aborto e eutanásia: dilemas contemporâneos sobre os limites da vida. Physis: Revista de Saúde Coletiva, 18(1), 77-103. http://doi.org/10.1590/S0103-73312008000100006

Herzlich, C., \& Pierret, J. (2005). A disease within a public space: AIDS in six french newspapers. Physis: Revista de Saúde Coletiva, 15, 71-101.

Jovchelovitch, S. (2001). Social Representations, Public Life, and Social Construction. In K. Deaux \& G. Philogène (Orgs.), Representations of the social: bridging theoretical traditions ( $\mathrm{p}$. 165-182). Oxford: Blackwell Publishers Ltd.

Kovács, M. J. (2003). Bioética nas questões da vida e da morte. Psicologia USP, 14(2), 115-167.

Leibing, A., \& Tournay, V. (Orgs.). (2010). Les technologies de l'espoir: la fabrique d'une histoire à accomplir. Québec: Presses de I'Université Laval.

Luna, N. (2010). Aborto e células-tronco embrionárias na Campanha da Fraternidade, ciência e ética no ensino da igreja. Revista Brasileira de Ciências Sociais, 25(74), 91-105.

Marková, I. (2006). Dialogicidade e representações sociais: as dinâmicas da mente. (H. Magri Filho, Trad.). Vozes.

Mattos, C. M. de, \& Siqueira, J. E. de. (2005). Mídia e bioética: repensando a ética na informação. Sociedade Brasileira de Bioética-SBB, 45.

Melo, J. (2001). Aborto na imprensa brasileira. In M. C. A. Oliveira \& M. I. B. da Rocha (Orgs.), Saúde reprodutiva na esfera pública e política na América Latina. (pp. 263-77). Campinas: Editora da Unicamp.

Menezes, R. A., \& Ventura, M. (2013). Ortotanásia, Sofrimento e Dignidade: entre valores morais, medicina e direito. Revista Brasileira de Ciências Sociais, 28(81). Recuperado de http://www.scielo.br/pdf/rbcsoc/v28n81/13.pdf 
Mesquita, M. (2004). O poder mediático. Teorias e Representações. Actas do VI Encontro de Sociologia nos Açores. Recuperado de http://www.fdiogo.uac.pt/pdf/Texto_Mario_Mesquita.pdf

Moscovici, S. (1976). A psicanálise, sua imagem e seu público. Petrópolis, RJ: Vozes.

Moscovici, S., \& Doise, W. (1992). Dissensions et consensus: une théorie générale des décisions collectives. Presses Universitaires de France-PUF.

Nascimento, A. R. A. do, \& Menandro, P. R. M. (2006). Análise lexical e análise de conteúdo: uma proposta de utilização conjugada. Estudos e Pesquisas em Psicologia, 6(2), 72-88.

Pazello, M., \& Corrêa, S. (2002). Aborto: mais polêmica à vista. Olhar sobre a mídia. Belo Horizonte: Mazza, 147-183.

Ribeiro, D. C. (2006). Autonomia: viver a própria vida e morrer a própria morte. Cad. Saúde Pública, 22(8), 1749-1754.

Rosemberg, F., \& Andrade, M. P. de. (2012). Infância na mídia brasileira e ideologia. In A. M. Jacó-Vilela \& L. Sato (Orgs.), Diálogos em Psicologia Social (pp. 285-307). Rio de Janeiro: Centro Edelstein de Pesquisas Sociais.

Simoneau, A. S., \& Oliveira, D. C. de. (2015). Representações sociais e meios de comunicação: produção do conhecimento científico em periódicos brasileiros. Psicologia e Saber Social, 3(2), 281300. http://doi.org/10.12957/psi.saber.soc.2014.14478

\author{
Endereço para correspondência \\ Edclécia Reino Carneiro de Morais \\ Universidade Federal de Pernambuco - UFPE \\ Departamento de Psicologia \\ Centro de Filosofia e Ciências Humanas, $9^{\circ}$ andar, Cidade Universitária, CEP 50670- \\ 901, Recife - PE, Brasil \\ Endereço eletrônico: edclecia@gmail.com \\ Renata Lira dos Santos Aléssio \\ Universidade Federal de Pernambuco - UFPE \\ Departamento de Psicologia \\ Centro de Filosofia e Ciências Humanas, $9^{\circ}$ andar, Cidade Universitária, CEP 50670- \\ 901, Recife - PE, Brasil \\ Endereço eletrônico: renatalir@gmail.com \\ J oanna Luiza da Cunha Pontes \\ Universidade Federal de Pernambuco - UFPE \\ Departamento de Psicologia \\ Centro de Filosofia e Ciências Humanas, $9^{\circ}$ andar, Cidade Universitária, CEP 50670- \\ 901, Recife - PE, Brasil \\ Endereço eletrônico: joannaluizapontes@gmail.com

\section{Larissa de Siqueira Coelho} \\ Universidade Federal de Pernambuco - UFPE \\ Departamento de Psicologia \\ Centro de Filosofia e Ciências Humanas, $9^{\circ}$ andar, Cidade Universitária, CEP 50670- \\ 901, Recife - PE, Brasil \\ Endereço eletrônico: coelholarissa8@gmail.com
}


Edclécia Reino Carneiro de Morais, Renata Lira dos Santos Aléssio, Joanna Luiza da Cunha Pontes, Larissa de Siqueira Coelho

Recebido em: 30/11/2015

Reformulado em: 29/11/2016

Aceito em: 29/11/2016

\section{Notas}

* Psicóloga, mestre em psicologia pela Universidade Federal de Pernambuco - UFPE. Doutoranda do Programa de Pós-Graduação em Psicologia da UFPE - Recife, Brasil. ** Psicóloga, graduada pela Universidade Federal de Pernambuco - UFPE Recife, Brasil. Mestre e Doutora pela Université de Aix-Marseille. Professora do Programa de Pós-Graduação em Psicologia da UFPE - Recife, Brasil.

*** Graduanda em psicologia pela Universidade Federal de Pernambuco - UFPE Recife, Brasil.

**** Psicóloga pela Universidade Federal de Pernambuco - UFPE. Mestranda do Programa de Pós-Graduação em Psicologia da UFPE - Recife, Brasil. 